\title{
Making a Debut in Teaching: Uncovering Prospective Teachers' First-time Teaching Experiences in Schools
}

\author{
Nadia Gilani ${ }^{1}$, Syed Abdul Waheed ${ }^{2, *}$, Asia Shaheen ${ }^{3}$ \\ ${ }^{1}$ Department of Teacher Education, University of Okara, Okara, 56300, Pakistan \\ ${ }^{2}$ Department of Educational Research \& Assessment, University of Okara, Okara, 56300, Pakistan \\ ${ }^{3}$ School Education Department, Govt of the Punjab, Pakistan
}

Received July 24, 2020; Revised August 22, 2020; Accepted September 29, 2020

\section{Cite This Paper in the following Citation Styles}

(a): [1] Nadia Gilani, Syed Abdul Waheed, Asia Shaheen, "Making a Debut in Teaching: Uncovering Prospective Teachers' First-time Teaching Experiences in Schools," Universal Journal of Educational Research, Vol. 8, No. 11, pp. 5443 - 5452, 2020. DOI: 10.13189/ujer.2020.081147.

(b): Nadia Gilani, Syed Abdul Waheed, Asia Shaheen (2020). Making a Debut in Teaching: Uncovering Prospective Teachers' First-time Teaching Experiences in Schools. Universal Journal of Educational Research, 8(11), 5443 - 5452. DOI: 10.13189/ujer.2020.081147.

Copyright@2020 by authors, all rights reserved. Authors agree that this article remains permanently open access under the terms of the Creative Commons Attribution License 4.0 International License

\begin{abstract}
First-time teaching is a transitional phase for novice teachers and it is an exciting experience and challenging task that needs to examine qualitatively. The purpose of the study is to explore prospective teachers' teaching experience as they practically live through teaching in the classroom for the first time in their lives. The phenomenological research approach was employed to explore the lived experience of thirteen teachers who were selected purposively from public and private schools in a district of the province of Punjab, Pakistan. Data were collected by interviewing the participants in an open-ended form of questions. The emergent main themes include debut in the classroom, managing classrooms, providing instructions, supported by cooperative teachers and support from school. The analysis of the themes and sub-themes revealed that prospective teachers experienced teaching quite differently from their expectations. The handling of the teaching situation became both challenging and exciting for them. The results have implications for prospective and novice teachers and educators, school administrators and experts of pre-service teacher programs who can make a plan to improve teaching conditions and enrich teaching experiences in the schools.
\end{abstract}

Keywords Lived Experience, Prospective Teachers, First-time Teaching, Teaching Practicum, Pre-service Teacher Training, Pakistan

\section{Introduction}

First time teaching is considered to be an exciting activity that shapes the concept of teaching and informs novice teachers for teaching and experiencing the phenomenon in a particular way. First time teaching experience can be positive or negative and contributes to teachers' success or failure in the future that helps make decisions if they have to take teaching as a profession or not. It was explored by Saenz-Lopez, Almagro, and Ibanezin (2011) that the initial experiences of prospective teachers can be inconsistent in some unfamiliar conditions, which results in anxiety, emotional reaction, tension and some kind of insecurity. Their level of interest, confidence and nature of feelings may become significantly important when they enter the classroom for the first time to teach school children. It has been observed that the first-time experience of prospective teachers brings difficulties for them and sometimes happiness and excitement. According to Ozmen (2008), prospective teachers face many problems during their exposure to teaching in schools. Grossman, Hammerness and McDonald (2009) discovered that teaching practice was a challenging task for prospective teachers. Moreover, the realities of classroom and expectations of prospective teachers have an apparent clash (Demirbag, Ünişen, \& Yesilyurt, 2016).

The prospective teachers' continuous professional development and learning process is an integral part of teaching practice so that their level of confidence, interest 
and knowledge of teaching strategies can be reinforced through teaching in the schools. Danielewicz (2001) argued that "prospective teachers' understanding of their professional self is shaped by teaching practice" (p. 79) and they should be provided with the rich experience and opportunity to teach for a longer period in the schools. Nevertheless, many challenges are faced by prospective teachers as time management, student assessment, lack of right relationship with school administration, lack of teaching skills, lack of understanding of students' behavior, and discipline (Sarpkaya, Cake Mark, \& Acer, 2010). According to Loughran, Mulhall, and Berry (2008), teachers suffer from anxiety, tension and inferiority complex due to lack of practice in teaching. The prospective teachers having first time teaching experience sometimes found that students' behavior did not fulfill their expectations (Sarnivaara \& Sarja, 2007). Also, Murshidi, Konting, Elias and Fooi (2006) noticed that novice teachers found teaching tasks a very complicated process.

Prospective teachers confront several challenges while engaged in a teaching practicum in schools. Carre (1993) argued that many problems arose due to their lack of professional knowledge and skill and it remained an important issue. Similarly, Peterson and Spencer (1990) stated that school culture could not be changed and prospective teachers had a great challenge to adjust themselves in that setting without manipulating anything against the established norms and values of that school setting. It was described by Scott (2015) that prospective teachers find it challenging to design and organize the learning activities due to lack of coordination among faculty and prospective teachers themselves. There is also a lack of a shared understanding of what and how they should proceed with their teaching activities. In some instances, they are not experts in subject content and teaching pedagogy. Due to such factors, it is tough to have control over the class and maintain discipline.

Consequently, they cannot satisfy student questioning due to their lack of knowledge. Sometimes, prospective teachers realize that they are not competent in organizing learning activities (Rink, 2006; Shulman, 2004). Ball and Forzani (2009) discussed that prospective teachers remain confused by on-going teaching activities because they do not have any practical exposure earlier in the real situation of teaching in the classroom. It is argued in the literature that prospective teachers possess merely theoretical knowledge and therefore, their understanding of teaching practices cannot be improved spontaneously. It was found that the environment of a classroom in a school cannot be understood while studying in a university classroom because there is a difference between two situations (Khan, 2013; Schulz, 2005). Trent (2012) commented that in schools, classrooms are traditional and their main focus is on preparation of examinations and interactive methods are neglected. According to Kyriacou and Kunc (2007), disruptive behavior of students, workload and low status of prospective teachers are the main reasons for their lack of interest in school teaching.

There is also a lack of intrinsic and extrinsic motivation for joining schools for practicing teaching. The prospective teachers should not be over-burdened as they need to have time to learn to develop their professional identity. According to Mehmood and Iqbal (2018), complications in teaching professions, lack of resources, not proper mentoring, the disparity between their expectations and teaching description, lack of teaching support and realities of the job, all these challenges create dissatisfaction, frustration and anxiety among prospective teachers. Nevertheless, the present research makes an attempt to grasp the understanding of prospective teachers who are teaching first-time in their life and the researchers intend to explore that how it is like to teach the first time in the classroom of public and private schools.

\subsection{Purpose of the Study}

Prospective teachers spend a significant time of their pre-service training in studying theories of the teaching, learning and teaching profession. They teach in primary, middle and secondary schools during their training for a short and extended period. Most of the prospective teachers had not got the opportunity to teach in schools. Teaching first-time in the schools is a unique and characteristic experience for most of them and they find themselves in a different 'state of mind' and academic environment. The nature of teaching can be elaborated through exploring the answer to the question of how it is like to teach in a school for the first time in one's life. The purpose of the study is to unveil this experience of prospective teachers who are engaged in teaching practice in public schools of a district in the province of Punjab, Pakistan.

\subsection{Research Questions}

The researchers attempted to explore the answers to the following research question for an understanding of first-time teaching experience in the life of prospective teachers.

1. What experiences do prospective teachers have during their first-time teaching in schools?

2. How do prospective teachers respond in the classroom during their first-time teaching?

3. How do prospective teachers interact first time with the students while teaching in the classroom?

\subsection{Significance of the Study}

The study uncovers prospective teachers' teaching experience who find themselves in a challenging situation while being the first time in a formal classroom setting and they feel hesitation, anxiety and tension. The researchers attempted to disclose how do prospective teachers 
experience the phenomenon of teaching in a school at the very first time. The exploration of first hand and first-time teaching experience will provide the future novice teachers to understand the nature of such experiences and it will help them in adapting to a specific classroom situation when they would join the teaching profession. They can understand the nature of possible problems such as classroom management, creating discipline, acquiring specific teaching skills, and understanding first-time interaction with students. Being aware of the nature of this teaching experience, the training institutes, cooperative teachers and schools and supervisors of prospective teachers can benefit from the outcomes of the study. Also, the results of the study will be useful to inform the objectives and curricula of pre-service teaching programs and it will add to the existing literature on the phenomenology of first-time teaching in schools.

\section{Methods}

In qualitative research, phenomenology aims to focus on a particular group of participants to grasp the detailed description of the nature of the phenomenon under investigation. In such studies, human experience is studied and a detailed and in-depth description of the experience is interpreted through participants' lived experiences (Creswell, 2007, 2013). This is a suitable methodology in understanding the situation of prospective teachers they experienced during the first-time teaching in schools because a deep understanding of the phenomenon can be attained through reflecting on the consciousness experiences of the teachers (Zeeck, 2012). Also, it is asserted in phenomenology that scientific investigation is only valid when the researcher gathers information through a rich description of participants to understand the essence of the experience (Moustakas,1994; Pinzon, 2016).

\subsection{Participants}

In a phenomenological study, the sample should consist of 5-25 participants (Creswell, 2018). Therefore, thirteen participants who were engaged in teaching practice in eight boys' and girls' schools in a district of the Province of Punjab were selected purposively. The participants of the study did not yet experience teaching in schools and they were in the $3^{\text {rd }}$ semester, studying in a department of teacher education in a provincial university and a federal open university in Pakistan. They were exposed first-time to teaching in schools and they confronted pleasant and unpleasant conditions.

\subsection{Data Collection}

In addition to the interview, observation can be used in a phenomenological study. However, it was assumed that the nature of prospective teachers' teaching experience would be distorted that will hurdle to understand the phenomenon with its 'true' description (Creswell, 2018). Whereas, an interview focuses on two questions: What experiences do you have in connection with the phenomenon (Moustakas,1994) and how the situation influenced you and shaped your mindset in terms of that particular phenomenon (Creswel, 2013).

A semi-structured interview guide, along with a short questionnaire, was used to identify some of the relevant characteristics of the study participants. Initially, the participants were asked to write their first-time teaching experience that reflected their understanding of the concept of teaching and this phenomenon. A semi-structured interview guide was developed based on these written reflections. Stuckey (2013) described that this type of interview has an outline of questions like a structured interview but it is flexible and the researcher can modify questions according to situations. Alshenqeeti (2014) added that it is the most common type of interview used in qualitative research and it can be conducted in groups as well as with individuals. On average, sixty minutes were allotted to each interviewee to explore the lived experiences of teaching. Some of the questions asked during the interview include: What happened when you first-time entered the classroom? How was it like for you to teach first-time in this classroom? What challenged you? How did you experience students' behavior? How was it like for you to manage the classroom discipline?

\subsection{Data Analysis}

In qualitative research, data gathered through an interview or any other methods are transcribed in the form of a text. First codes were recognized from the interview transcripts. According to Boyatzis (1998), a good code always achieves the qualitative richness of phenomenon. The validation process of codes was established to ensure the integrity of these codes and to remove the biases of researchers during interpretation. Before encoding the data, it was read again and again. From these codes, themes were identified after careful analysis. All the information from the semi-structured interview was transcribed and themes were sorted. Words and sentences were grouped and clustered to find sense and underlying meanings and they were organized in the form of categories and themes (Creswell, 2018). In this process, the researcher attempts to find the universal meaning of the phenomenon and develops its deep and profound understanding (Moustakas,1994; Pinzon, 2016). Prospective teachers' experiences, challenges and their interaction with students on the very first day were searched out and their typical words, phrases and statements were given in quotes to help understand the teaching phenomenon through the lenses of the participants' experiences (Creswell, 2018). The participants' names given in the text were not their real names but the fictitious ones. 


\section{Results}

The first day of teaching is often characterized by mixed feelings of happiness, excitement, anxiety and fear. In the same way, the very first exposure of prospective teachers to school becomes unforgettable for their pleasant and unpleasant experiences, as reflected by the data collected through interviewing them.

\subsection{Debut in the Classroom}

Being a teacher, entering the first time into the class, is a significant event. It is associated with different feelings and emotions depending upon the experience of a teacher. Participants of the study had also experienced mixed feelings and emotions when they first time entered into their classrooms. Some of them were very happy and excited while some of them got tensed, nervous, irritated and disappointed too. Explicitly talking about prospective teachers, most of the time, there was a problem of being recognized as a novice teacher due to their youthful looks. As one of the participants "Ayesha" from $3^{\text {rd }}$ semester expressed her "irritation" about her entrance in the classroom in this way:

I was very excited on my first day in school, but in my debut class, nobody was ready to consider me a teacher. Even students kept on calling me "sister." It was irritating for me to listen to this because I was not expecting such words in a formal classroom, and all my excitement went into the air.

The participants explained the situation mentioned above that as most of them were younger than their cooperative teachers so, it was difficult for the students to accept them as their teachers. Another participant named "Hafsa" expressed that when she first time entered the classroom, she realized that everyone was looking at her oddly. She explained her condition:

Their looks made me so nervous that my heart started beating fast. I wanted to sit but could not be able to use the teacher's chair. I forgot that I could sit on that and could be relaxed for a moment to compose myself.

Most of the study participants felt the same as they were exposed to a large number of students the first time in their life when hey interacted with them. Another reason for being nervous was the presence of a cooperative teacher who was not very welcoming towards them. One prospective teacher named "Iqra" shared her disappointment on her first entrance describing that:

I exposed to a class that was overcrowded and loud. Their teacher guided me to the classroom door and went back. I tried to introduce myself but in vain. I tried hard to make them silent so that I could introduce myself but all in vain. Teaching was a dream for me. When there came a time to turn this dream into reality, I felt that It would be a dream "only" as all my expectations dashed to the ground.

Nevertheless, some of the participants showed positive feelings while they entered their classrooms. They were quite happy and satisfied with their first-time exposure to school and the class. One of the prospective teachers, "Fatima" joyfully expressed that she was "more than comfortable" on my first day in the classroom. She reflected that "I felt myself over the moon when a student called me "teacher" and had a great sense of pride." Another participant also experienced a heartwarming response from a student when she entered the class. She described that "I could not forget respect given by one of the students' who cleaned the chair with her hands for me. She got such an extraordinary welcome from a student on her very first day".

Overall, study participants experienced mixed feelings and emotions regarding their first-time entry into the classrooms that were associated with various aspects of the phenomenon.

\subsection{Managing Classrooms}

Teaching does not mean only delivering the content but also involves active engagement to manage the classroom. For novice teachers, it was a challenging task that required hard work and devotion. It includes dealing with children with disruptive behavior, managing overcrowded classrooms, keeping classroom environment productive for teaching. These aspects of participants' experiences with managing the classes are described below in the form of sub-themes.

Experiencing overcrowded classrooms. One of the essential tasks regarding discipline was managing the overcrowded class. According to most of the study participants, classrooms in public schools were large and had many more students than their capacity as one of the participants' named “Rafia” expressed:

I was not able to handle such a crowded and noisy class. I did not know even what I was teaching there. Students were not ready to listen to me. I think a single teacher could not handle such a vast class.

During the first exposure, it was complicated for the new teachers to handle crowded and noisy classrooms. The participants expressed their "helplessness and hopelessness" under such situations. They further elaborated that this situation required strict behaviour by us, whereas they were not allowed to do that in schools. These large size classes were an added difficulty in their teaching. Another participant, "Hira" reflected on the situation that:

Most of my class time gone wasted in keeping the students quiet and made them seated. Then what time left for teaching? By doing this exercise, she lost all the concentration and became demotivated, which severely affected the teaching and learning process.

The participants explained that due to the lack of regular 
cooperative teachers, schools need to have large classrooms, which caused many discipline problems. On the contrary, some of the participants expressed encouraging views regarding managing huge classes. They believed that when one has a passion for teaching, such an issue could not stop oneself from taking it seriously. One of the participants named "Hina" remarked that "knowledge of teaching and practical teaching were two different things. Though there were some difficulties in managing students, it was not a big problem. It could be handled by developing an understanding of the students". Being new to the students, a rapport needed to be established and once it was done, then things would be in better control. Another participant in the study, "Fatima" described her first joyful experience that as she entered the class, despite a large number of students inside, everyone started looking at me by saying to each other "our new teacher...., how pretty is she". They became so attentive and started taking my introduction. When I left their class, I was overwhelmed by their reception.

Dealing with disruptive behavior. Another major challenge in managing the classroom is to deal with the disruptive behavior of students effectively. It is imperative to minimize the distractions created by such behavior to provide maximum input into the classroom instructions. Prospective teachers felt the same in this regard. While handling a large number of students was itself a task, challenging behaviors added injury to it. The prospective teachers had first-time interaction with the class and they did not have much information regarding the characteristics of such children. One of the participants of the study, "Iqra" reflected on her lousy experience that "boys were more difficult to handle than girls as they were more troublesome". She shared her experience of taking up boys' classes for the very first time and she started "crying" as no one was listening to her. This issue became more severe in middle or higher classes of boys as another prospective teacher, "Rafia" recalled her annoying experience of indulging in such a situation. She described

Two boys had a little argument, which in a minute turned into a big fight. I tried my best to resolve the issue, but I failed. Due to that, my whole day spoiled, I could teach them anymore and it affected the whole class.

Even its equally difficult to handle such behavior by the prospective male teachers. For example, one of the male participants, "Haris" expressed his experience that "it was started well in the beginning, but a group of the most disruptive boys made my day worse." He continued by explaining:

That group did not seem interested in learning. They listened to me patiently for some time, but as I initiated instruction, they started disturbance by loud talking to each other, and in an instance, they made paper planes and started throwing in the classroom. This made the whole class a fun place, and other

\section{students also joined them.}

Almost all the study participants had unpleasant experiences regarding disruptive behaviors. They explained that even their regular teachers could not handle them despite knowing them very well and being with them for a long time. So, for them, it was a routine to face this type of behavior as handling such students could be time taking and required a strong rapport.

Safe and clean environment. The clean and safe classroom environment is directly related to effective teaching. Proper and well-maintained classroom increases teachers' instruction time and minimizes the disturbances and instructions. The Prospective teachers were very disappointed regarding the cleanliness and safety conditions of public schools' classrooms. They expressed that cleanliness conditions were poor as there were no sweepers in the schools and students had to clean their classrooms themselves. Moreover, most of the classrooms had untidy and broken furniture, even a few classes were deprived of any furniture and the students had to sit on mats.

In the morning, students used to clean their classroom floors and writing boards, which wasted a lot of their time. One of the participants, "Fareed" shared his experience that "when I entered my classroom, three students were sweeping the floor with a broom and the whole class was full of dust that he could not breathe for some time." Another participant named "Mehwish" remarked that "There was no dustbin in the classroom and students were in the habit of throwing wrappers, pages and wastage of their pencils on the floor. On stopping them from doing so, they curiously asked me, "then, where to throw."

Similarly, classrooms were having a shortage of furniture and what they had was also not in good condition. A participant, "Rafia" described that "the table for the teacher missed an arm and bricks were placed under the table to balance it. The chair for the teacher was also not in good condition that I decided not to sit on that". In the same way, students had to sit under the sky on the mats, even in extreme weather conditions. She added that "how one can make them teach in such vulnerable conditions."

On the other hand, few participants were happily surprised by the cleanliness conditions of their classrooms, which had a pleasant effect on their first-day teaching. One of the prospective teachers described:

On my entrance into the classroom, a neat and tidy room with a bunch of flowers on the teacher table welcomed me. Furniture was also in good condition and arranged well. It saved lots of time and I was instantly motivated for teaching.

Most of the participants were of the view that a smart and safe classroom was one of the factors that contributed to the pleasant experience and effective teaching. Teachers can save much time and take maximum advantage of spending given time in teaching and instructional activities. 


\subsection{Providing Instructions}

Effective teaching and learning are highly dependent on the use of appropriate teaching methods, instructions and availability of teaching resources. They save teachers' time, facilitate learning and make the content easy and understandable. Herbert and Grous (2007) stressed that continuous learning is possible through the use of useful instructions and instructional resources in the classroom, which is the responsibility of a teacher. This central theme is divided into sub-themes for better explanation and understanding i.e. methods of teaching, language barriers and limited availability of resources.

Methods of teaching. On the very first day, most of the prospective teachers were nervous and confused while starting instructions. Many students reflected that there was a hell of a difference between bookish knowledge and its actual implementation. We were taught many methods and techniques of teaching in the university but it was tough to practice those methods with large classes. They explained that "there was only one method used in school and that was lecture method." Students were in the habit of "cramming" without understanding the concepts of anything. Many participants elaborated that they tried to "use interactive methods," but initially, students were not habitual of participating and sharing their thoughts.

Many participants tried to adopt a different method than lecture and had few lessons with the activity method. They made flip cards, charts and models with the students. It was all new for them that made them excited and involved them in the teaching-learning process. Students learned a lot through activities than the lecture method and equally enjoyed it. One of the participants "Hira" notably stated that:

Having activity done twice in the class, my students started waiting for the next day's class impatiently and always stressed to do some activity again. The happiness on their face while taking part in activities could not be described in words. It was my most significant success during teaching practice.

As almost all of them were having the first experience of teaching in a real setting, many of them had low confidence levels, but on every other day, it improved a lot. One of the participants shared her nervousness that "students questioning disturbed me," but after a week or so, she felt more confident and composed. She explained that "teaching is just like driving a car, once you learn, then no more worries."

Language barrier. Language is a medium of instruction in the teaching-learning process. It improves the instructions when imparted in the national or local language of an area of the country. According to study participants, all the interaction between students and teachers took place in the Urdu language but most of their textbooks were in English. Regarding the language of instruction, the prospective teachers agreed that "English as a medium of instruction was a real challenge for them." The students could not understand the books written in the English language and forced to rote the content. One of the study participants shared that "on my first day when I asked my students about what they learned previously, more than half of the class was unable to answer." How could I able to teach in such a situation". A couple of other participants added regarding a similar situation that most of their textbooks were in English and students were not comfortable with this language. The condition of students was such that they did not know how to hold these books, even they hold them in the wrong direction. Students were over-burdened due to the problem that they were not being taught in their national language and suffered a lot. This situation was very hurting for me. On the other hand, the students were more comfortable with the books written in their national language (Urdu). It was comparatively easy to instruct them and their learning was better in those subjects.

Limited instructional resources. The availability of required instructional resources is an essential component of compelling teaching experiences. Students can benefit from teaching when they learn with the help of appropriate teaching and learning resources. In the public schools where the study participants were teaching, they found a scarcity of teaching resources. Even in some of the schools, the necessary teaching aids were not available. For example, one of the participants, "Hina" described that:

It was shocking to me when I started teaching and wanted to write something on board, I came to know that there was no board and marker available in the class. Then I thought my teaching was only a wastage of time.

Whereas in most of the schools, only a few essential resources were available in the classrooms and the rest had to be arranged by the teachers or students themselves. The students also brought the charts for displaying in the class. In this regard, another participant remarked:

I wanted to erase the written work on the board and needed a duster, a dirty piece of cloth was given to me by a student. On asking, I was told that they did not have any duster and used to clean the board in the same way, or sometimes it was cleaned even with the hands.

Rapport with the students. Developing a good relationship between student and teacher can be highly influential in the teaching-learning process. It can make a massive difference in the output of teaching. Prospective teachers had memorable experiences while talking about establishing a rapport with their students. Most of them found that they developed an amicable relationship, which made them "favorite" of their students. Students loved to have them in their classes even if they did not have any lectures in their classes.

A participant, "Mehvish" shared happily that "her 
students used to appreciate her dress and makeup and waited eagerly what I would wear it the next day." The other participants also had similar experiences. They explained that their regular teachers did not give them space to develop a friendly relation with them and remained at a distance. One of the exciting events quoted by a participant was that "once my class's regular teacher saw me talking and smiling with the students. When I left the classroom, she came to me and said, "Do not try to be frank and close to them. They would disturb us when you left".

As the study participants were young, fresh and friendly, students became very close to them and started loving them. They were also impressed by the way they taught in the class. So, all these factors made prospective teachers "the most loving teacher." Even more intense reactions were seen when these teachers were going to leave the school after the teaching practice was over. Almost every class became "emotional," and many of them were "crying." The students gave them hand-made "small gifts and cards." Most of the students took a promise from their teachers to come back again to their school. Overall, most of the prospective teachers were able to establish a good rapport with their students, which helped them in getting the better instructional output.

\subsection{Support by Cooperative Teachers}

Regarding the support provided by the cooperative teachers, the participants of the study had mixed opinions and experiences. These cooperative teachers were the regular teachers of those classes assigned to the prospective teachers. One common aspect noted from participants' experience was that the cooperative teachers were welcoming in the sense that they shifted the responsibility of teaching to us and they could relax for a few weeks. Other than this, most of them criticized them and did not guide them properly. For example, a participant described that my cooperative teacher sat in the class in anger and criticized me for tiny things. She further explained that:

Once, on coming few minutes late in the class, my cooperative teacher scolded me as if I was her student and even worse was that she complained to my supervisor that your student was non-serious in teaching and did not know how to teach.

Whereas, a couple of the prospective teachers had great "chemistry" with their cooperative teachers and learned a lot from them. They elaborated that whenever they encountered any instructional and behavioral problems, their cooperative teachers helped them. One of them expressed his gratitude towards him, describing that:

My first-time teaching exposure was made easy with the help of my cooperative teacher. He guided me so well that I found a clear difference in handling my class at the end of teaching practice. I was so grateful to him for his support.

\subsection{Support from School}

Support from school administration and the environment plays a vital role in making teachers' first experience pleasant or unpleasant. Most of the prospective teachers did not find an environment conducive to the teaching process. Most of them showed dissatisfaction regarding support from the head teacher and the overall environment. A participant expressed great disliking towards the school environment. She found a lot of anxiety and fear of all the regular teachers and the headteacher. Due to the strict inspection from higher authorities, they all remained tensed of fulfilling all criteria. One of the participants shared her experience:

One day, one of their regular teachers was absent and an official visit was expected. The headteacher was in so much stress that she asked me to pretend to 'become' that teacher for one day so that they could maintain the required teacher attendance. It made me so nervous and fearful.

Few of the participants described that they were not dealt with appropriately by the administration. Some of them were getting involved by the administration in other activities than teaching. A participant stated that "school administration did not take us seriously and was quite reluctant to assign the teaching responsibility of a class." Another participant shared that she was assigned the task to "maintain practical notebooks" of students and also assigned "managing canteen" with a regular teacher. She remarked disappointingly that "my desire to teach remained unfulfilled."

\section{Discussion}

It was found that prospective teachers entered to teach in the schools for the first time with enthusiasm but some of them became hopeless due to unexpected situation and challenges and others remained firm and did not lose courage and had a pleasant experience. Some of the prospective teachers had less command over the subject matter and teaching skills and they did not understand how to handle the situation satisfactorily. It also became challenging to satisfy the students and they had low confidence in handling them. It was tedious for them to control the large classrooms.

Sometimes they call it hard and sometimes a challenge and tiring task. Also, an apparent clash was noticed between prospective teachers' expectations and real situations in the school. Berl (2004) stated that prospective teachers come with fresh thinking, imagination, eagerness, passion and with certain beliefs in teaching and they had set ideals about this profession but they have lack of confidence.

The prospective teachers have only read theoretical concepts and such type of practical situation is new for 
them. They are not mentally prepared to handle these situations in real classrooms. According to Flores and Day (2005), teachers face problems when they come into real classroom situations but the time provides them an understanding of students' needs and they also learn about teaching strategies. Gilbert (2005) supported the cooperation of experienced teachers for prospective teachers. They want to become good teachers but sometimes conditions change their views. Also, the school administration hesitates to accommodate them, considering as intruders in their matters. Such factors create anxiety, tension and bitter feelings among them.

It is a bitter reality that government schools have fewer facilities and there is an intense need to introduce real situations in training courses. Any teaching pedagogies cannot be practiced due to a tough scheme of study (Kilgore, Ross, \& Zbikowski, 1990). It is not possible to change the conditions of school at once but teacher education should be more relevant to understand the prevailing situations of classrooms so that they could be able to teach and apply different strategies for overcrowded classes. Wanzarae (2007, p.349) suggested that training institutions should train prospective teachers in teaching methods and skills so that they can become effective teachers and adjust in the classroom atmosphere.

\section{Conclusions}

First-time teaching, especially for the prospective teachers, is a crucial practice as it is marked with varied experiences which help them to make judgments regarding their future profession. The study figures out the nature of this phenomenon through the descriptions of prospective teachers.

It was concluded from the descriptions of the participants that their first entrance into the classrooms had unique feelings due to their debut exposure to the real-world setting of the school. Where there were feelings of excitement, joy and happiness, there were also feelings of nervousness, anxiety and fear. Their experience was also associated with many challenges regarding instructions and management of the classrooms. They felt much difficulty in teaching and managing the large-sized classrooms. Owing to the overcrowded classrooms, most of the participants struggled in maintaining discipline and dealing with the student with disruptive behavior. This happened mostly due to the "unfamiliar" classroom environment and lack of understanding of students' backgrounds, needs and preferences but things started getting better over time with the help of the cooperative teachers. Moreover, the classrooms had severe issues regarding cleanliness and the availability of proper furniture. Most of their time was wasted in trying to create a "supportive" environment for teaching.

Regarding instruction, most of the participants found that there was a vast difference in knowing about teaching and teaching in real school setting. They were taught many teaching methods but they found themselves unable to use many of them due to the limitation of resources, first-time exposure and class sizes. There was a scarcity of even essential instructional resources, which made teaching more challenging for them. Another hurdle was the language barrier. Most of the teaching was assumed to be carried out in English due to English as a medium of instruction but students were not comfortable in learning so.

Being able to develop a good rapport with the students was the most exciting and memorable part of first-time teaching. Most of the prospective teachers were overwhelmed with the love and respect given to them by their students, whereas a little bit disappointed by the non-cooperation of their cooperative teachers. According to them, most of the cooperative teachers started having inferiority or superiority complex due to the priority given to prospective teachers by the students. Some of the prospective teachers found regular teachers cooperative and supportive. Nevertheless, there was a lack of support from the school administration. The headteachers took prospective teachers as a burden and mostly assigned them the tasks other than teaching, resultantly, made them disheartened and demotivated. Moreover, the school environment was not comfortable as there was an element of fear of being inspected by the higher authorities. This kind of environment was one of the causes of anxiety among the participants of the study.

The study has implications for school improvement and enhancing quality of teaching practices. The study suggests that how the prospective teachers particularly those who are experiencing teaching for the first time can make their experiences positive and pleasant. The future researchers should investigate how do the students experience with novice teachers who are teaching first time in their lives.

\section{Trustworthiness of the Study}

The trustworthiness of a study means maintaining the degree of confidence in the collection of data, interpretation and methods which are necessary to ensure the quality of research work (Pilot \& Beck, 2014). Necessary criteria for maintaining trustworthiness consist of credibility, dependability, confirmability, transferability (Lincoln \& Guba, 1985), and authenticity, which was added later by Guba \& Lincoln (1994). The credibility of research, or trust in the truth of research and hence findings, are the most important criteria (Polit \& Beck, 2014). The credibility of the study can be achieved by using standard procedures in qualitative research. Triangulation and Member checking are two techniques to establish credibility in research. In this study, member checking was 
used to establish credibility. The data and its interpretation were shared with participants to confirm and clarify their intentions and to correct the errors if some information was misinterpreted and to have additional information.

\section{REFERENCES}

[1] Alshenqeeti, H. (2014). Interviewing as a data collection method: A critical review. English Linguistics Research, $3(1)$.

[2] Ball, D., \& Forzani, F. (2009). The work of teaching and the challenge for teacher education. Journal of Teacher Education, 60(5) 497-511.

[3] Berl, S. P. (2004). Insights into teacher development, child care information exchange. Implications of studies of expertise in pedagogy for teacher education. In $\mathrm{New}$ directions for teacher assessment. N.J: Princeton.

[4] Carre, C. (1993). The first year of teaching. In N. Bennett \& C. Carre (Eds.) Learning to Teach. London \& New York, Routledge.

[5] Creswell, J. W. (2007). Qualitative inquiry and research design: Choosing among five approaches (2nd ed.). Thousand Oaks, CA: Sage Publications, Inc.

[6] Creswell, J. W. (2013). Qualitative inquiry \& research design: Choosing among five approaches (3rd ed.). Los Angeles, CA: Sage.

[7] Creswell, J. W., \& Creswell, J. D. (2018). Research Design: Qualitative, Quantitative, and Mixed Methods Approaches (5 ${ }^{\text {th }}$ ed.). Los Angeles: Sage.

[8] Danielewicz, J. (2001). Teaching selves: identity, pedagogy, and teacher education. Albany, NY: State University of New York Press.

[9] Demirbag, B., Ünişen, A., \& Yesilyurt , A. (2016). Training of Critical Thinking Skills in Teacher Candidates and Placebo Effect: A Quasi-Experimental Study. Eurasian Journal of Educational Research (EJER) 16(63): 375-392.

[10] Flores, M. A. \& Day, C. (2005). Context which shape and reshape new teachers' identities: A multi-perspective study. Teaching and Teacher Education, 219-232.

[11] Gilbert, L. (2005). What helps beginning teachers? Educational Leadership, 62(8),36-39.

[12] Grossman, P., Hammerness, K., \& McDonald, M. (2009). Redefining teaching, re - imagining teacher education. Teachers and Teaching: Theory and Practice, 15(2), 273-289.

[13] Grossman, P., Compton, C., Igra, D., Ronfeldt, M., Shahan, E., \& Williamson, P. (2009). Teaching practice: A cross-professional perspective. Teachers College Record, 111(9), 2055-2100.

[14] Guba, E. G., \& Lincoln, Y. (1994). Competing paradigms in qualitative research. In N. Denzin \& Y. Lincoln (Eds.), Handbook of qualitative research (pp. 105-117). Thousand Oaks, CA: Sage.
[15] Khan, N. Z. (2013). Need for improvement of teacher education in the new millennium. International Journal of Secondary Education. 1(2), 4-7.

[16] Kilgore, K., Ross, D., \& Zbikowski, J. (1990). Understanding the teaching perspectives of first-year teachers. Journal of Teacher Education, 41, 28-38.

[17] Kyriacou, C., \& Kunc, R. (2007). Beginning teachers' expectations of teaching. Teaching and Teacher Education, 23(8), 1246-1257.

[18] Lincoln, Y.S., \& Guba, E. G. (1985). Naturalistic inquiry. Newbury Park, C A: Sage.

[19] Loughran, J., Mulhall, P., \& Berry, A. (2008). Exploring pedagogical content knowledge in science teacher education. International Journal of Science Education, 30(10), $1310-1320$.

[20] Mahmood, N., \& Iqbal, Z. (2018). Challenges faced by prospective teachers during teaching practice: Connecting theory to practice. Bulletin of Education and Research, 40(2), pp. 113-136.

[21] Moustakas, C. E. (1994). Phenomenological research methods. Thousand Oaks, CA: Sage.

[22] Murshidi, R., Konting, M. M., Elias, H., \& Fooi, F. S. (2006). Sense of efficacy among beginning teachers in Sarawak. Teaching Education, 17(3), 265-275.

[23] Ozmen, H. (2008). The influence of computer-assisted instruction on students' conceptual understanding of chemical bonding and attitude toward chemistry: A case for Turkey. Computer \& Education, 51(1).

[24] Peterson, M.W, \& Spencer, M. G. (1990). Understanding academic culture and climate

[25] New Directions for Institutional Research, 68, 3-18.

[26] Polit, D. F., \& Beck, C. T. (2014). Essentials of nursing research: Appraising evidence for nursing practice (8th ed.). Philadelphia, PA.

[27] Rink, J. E. (2006). Teaching physical education for learning (5th ed.). Boston, MA: McGraw Hill.

[28] Pinzon, A. J. G. (2016). A phenomenological study of lived experiences of teachers living in a meager income.

[29] Saarnivaara, M., \& Sarja, A. (2007). From university to working life: Mentoring as a pedagogical challenge. Journal of Workplace Learning,19 (1), 5-16.

[30] Saenz-Lopez, P., Almagro, B. J., \& Ibanez, S. J. (2011) Describing Problems Experienced by Spanish Novice Physical Education Teachers. The Open Sports Sciences Journal, 4, 1-9.

[31] Scott, L. C. (2015). The future of learning 3: What kind of Pedagogies for the 21st Century? Educational Research and Foresight, Working Papers. UNESCO.

[32] Schulz, R. (2005). The practice: More than practice. Canadian Journal of Education, 28(1/2), 147-169.

[33] Shulman, L. S. (2004). The wisdom of practice: Essays on teaching, learning, and learning to teach. San Francisco, CA: Jossey-Bass. 
[34] Stuckey, H. L. (2013). Three types of interviews: Qualitative research methods in social health. Journal of Social Health and Diabetes,1(2): 56-.59

[35] Trent, J. (2012). From campus to classroom: A critical perspective on approximations of practice in teacher education. Research Papers in Education, 1-24.

[36] Wanzarae, Z. O. (2007). The transition process: The early years of being a teacher. In T. Townsend and R. Bates (Eds.)
Handbook of teacher education (globalization, standards and professionalism in times of change), Netherland: Springer.

[37] Zeeck, Kirk A. (2012). A Phenomenological study of the lived experiences of elementary principals involved in dual-career relationships with children. Unpublished doctoral dissertations in leadership. The University of St. Thomas, Minnesota. 